\title{
Evaluasi Kinerja Crushing Plant di PT X Desa Cipinang, Kecamatan Rumpin, Kabupaten Bogor, Provinsi Jawa Barat
}

\section{Hafizh Eliansyah* , Sriyanti}

Prodi Teknik Pertambangan, Fakultas Teknik, Universitas Islam Bandung, Indonesia.

*hafizheliansyahh@gmail.com, sriyanti.tambang@yahoo.com

\begin{abstract}
With a total area of $\pm 100 \mathrm{Ha}$. The purpose of this study is to determine the obstacles that occur during production, to determine the availability and work efficiency of mechanical equipment, and to determine the production tonnage of crushing plant equipment. Processing of andesite minerals at the crushing plant unit of PT X consists of three stages, namely primary crushing using a jaw crusher (Metso C-140), secondary crushing using cone crusher 1 (CMC PCC4A) and tertiary crushing using cone crushers $2 \& 3(\mathrm{NH}-400)$. Data processing activities and research results at PT X consist of field activity procedures, crushing plant work cycles, crushing plant working time, crushing plant productivity, actual conveyor belt calculations, and calculation of conveyor belt production losses. Based on data on human barriers and mechanical devices, the value of mechanical availability is $94.77 \%$ and work efficiency is $94.83 \%$. Lossing materials that occur during the processing are divided into 5 stages, namely, primaru crushing $=0.25$ tons/hour, secondary crushing $=0.16$ tons/hour, teriary crushing $=0.14$ tons/hour, sizing $1=0.07$ tons /hour and sizing $2=0.03$ ton/hour. Production results of jaw crusher $=384.86$ tons/hour, cone crusher $1=384.70$ tons/hour, cone crusher $2=163.37$ tons/hour and cone crusher $3=163.65$ tons/hour. The products produced by this company consist of 6 types of products including split 12 , split 23 , screening, stone ash, and base course. The results of the crushing plant performance evaluation could not meet the production target of 380 tons/hour with a product production of 377.37 tons/hour.
\end{abstract}

Keywords: Primary Crushing, Secondary Crushing, Tertiary Crushing.

Abstrak. Luas wilayah keseluruhan \pm 100 Ha. Tujuan penelitian yaitu mengetahui hambatanhambatan yang terjadi saat produksi, mengetahui nilai ketersediaan dan efesiensi kerja alat mekanis, lossing materials selama proses produksi dan mengetahui tonase produksi alat crushing plant. Pengolahan bahan galian andesit pada unit crushing plant PT X terdiri dari tiga tahap yaitu primary crushing dengan menggunakan jaw crusher (Metso C-140), secondary crushing menggunakan cone crusher 1 (CMC PCC4A) dan tertiary crushing menggunakan cone crusher $2 \& 3$ (NH-400). Kegiatan pengolahan data dan hasil penelitian pada PT X terdiri prosedur kegiatan lapangan, siklus kerja crushing plant, waktu kerja crushing plant, produktivitas crushing plant, perhitungan belt conveyor secara aktual, dan perhitungan losses produksi belt conveyor. Berdasarkan data hambatan manusia dan alat mekanis didapatkan nilai ketersediaan mekanis $94,77 \%$ dan efisiensi kerja sebesar $94,83 \%$. Lossing materials yang terjadi selama proses pengolahan terbagi menjadi 5 tahapan yaitu, primary crushing $=0,25$ ton/jam, secondary crushing $=0,16$ ton/jam, teriary crushing $=0,14$ ton/jam, sizing 1 $=0,07 \mathrm{ton} / \mathrm{jam}$ dan sizing $2=0,03 \mathrm{ton} / \mathrm{jam}$. Hasil Produksi jaw crusher $=384,86$ ton/jam, cone crusher $1=384,70 \mathrm{ton} / \mathrm{jam}$, cone crusher $2=163,37 \mathrm{ton} / \mathrm{jam}$ dan cone crusher $3=163,65 \mathrm{ton} / \mathrm{jam}$. Produk yang dihasilkan perusahaan ini terdiri dari 6 jenis produk diantaranya yaitu split 1-2, split $2-3$, screening, abu batu, dan base course. Hasil evaluasi kinerja crushing plant tidak dapat memenuhi target produksi sebesar 380 ton/jam dengan produksi produk yang diperoleh sebesar 377,37 ton/jam.

Kata Kunci: Primary Crushing, Secondary Crushing, Tertiary Crushing. 


\section{A. Pendahuluan}

Berdasarkan data Badan Pusat Statistik (BPS), pertumbuhan ekonomi Indonesia pada tahun 2021 berada pada angka sebesar 7,07\%, sehingga menyebabkan Indonesia masih termasuk kedalam katagori negara berkembang. Indonesia sebagai negara berkembang terus melakukan upaya dalam bidang pembangunan infrakstruktur seperti, pembangunan jalan tol, jembatan, bandara, kereta cepat dan lain sebagainya. Pembangunan infrakstruktur tersebut menyebabkan kebutuhan akan batu andesit yang semakin meningkat dikarenakan agregat batu andesit dimanfaatkan sebagai bahan baku dalam pembuatan beton.

PT X merupakan perusahaan yang bergerak dalam sektor industri pertambangan bahan galian batuan andesit. PT X melakukan kegiatan tambang terbuka dengan metode tambang terbuka (quarry) dengan target produksi ROM 400 ton/jam dan target produksi crushing plant 380 ton/jam. Produk yang dihasilkan berupa split 1-2, split 2-3, screening, base course, abu batu yang sesuai dengan kebutuhan industri.

Kemampuan kerja dari unit crushing plant sangat mempengaruhi besarnya produksi, untuk meningkatkan kualitas andesit dilakukan evaluasi kinerja crushing plant dengan memperhatikan hambatan-hambatan yang terjadi pada alat crushing plant seperti faktor alat dan faktor manusia, hambatan tersebut tentunya akan menurunkan efesiensi kerja alat dan dapat menyebabkan tidak tercapainya target produksi yang diinginkan oleh perusahaan. Sehingga perlu dilakukan evaluasi kinerja crushing plant agar target produksi yang diharapkan oleh perusahaan dapat tercapai. Selanjutnya, tujuan dalam penelitian ini diuraikan dalam pokokpokok sebagai berikut.

1. Mengetahui hambatan-hambatan yang terjadi pada saat produksi crushing plant.

2. Mengetahui nilai ketersediaan mekanis, efisiensi kerja alat mekanis dan fisik dari mesin crusher.

3. Mengetahui loosing materials selama proses operasional unit crushing plant.

4. Mengetahui produksi produk crushing plant.

\section{B. Metodologi Penelitian}

Crushing plant merupakan rangkaian proses pengolahan bahan galian yang bertujuan untuk menghancurkan bongkah besar menjadi fragmen yang mempunyai ukuran yang lebih kecil. Crushing plant terdapat beberapa alat yaitu mesin crusher, sizing, hopper, dan belt conveyor, setiap alatnya mempunyai kesinambungan dalam suatu sistem kerja. Untuk dapat mencapai target produksi terdapat faktor yang berpengaruh yaitu feed, open side setting, close side setting jenis material, proses pengumpanan, spesifikasi alat crusher, kecepatan belt conveyor dan kapasitas alat crusher. Metodologi penelitian terbagi menjadi sebagai berikut :

1. Teknik Pengambilan Data

Teknik pengambilan data dapat dilakukan dengan data primer dan data sekunder, rincian data primer dan data sekunder meliputi :

a. Data primer, terdiri waktu produktif, jenis hambatan, durasi hambatan, ritase alat angkut, fill factor, kapasitas bucket, lebar hooper, open set, close set, density insitu, kecepatan belt dan data belt cut.

b. Data sekunder, terdiri dari spesifikasi alat, peta-peta dasar, data curah hujan, profil perusahaan, dan target produksi perusahaan.

2. Teknik Pengolahan Data

Teknik pengolahan data untuk mengevaluasi kinerja crushing plant dalam mengetahui produksi mesin crusher, data yang dibutuhkan meliputi, menghitung waktu efektif, efisiensi kerja, belt cut dan produksi alat angkut.

3. Teknik Analisis Data

Teknik analisis data dilakukan dengan cara memperhitungkan lebih rinci studi teknis yang dilakukan dengan beberapa parameter yang mempengaruhi optimalisasi produksi dari kegiatan crushing plant yang digunakan dengan metode belt cut. 


\section{Hasil Penelitian dan Pembahasan}

\section{Volume Hopper}

Hopper adalah alat penampung material ROM yang diperoleh dari site penambangan sebelum diolah pada unit crushing plant. Untuk ukuran dari hopper pada PT X didapatkan ukuran dengan panjang $8.93 \mathrm{~m}$, lebar $5.58 \mathrm{~m}$ dan tinggi $4.58 \mathrm{~m}$. Volume hopper dapat dilihat pada tabel 1.

Tabel 1. Dimensi Hopper

\begin{tabular}{|c|c|c|c|c|}
\hline Alat & Panjang (m) & Lebar (m) & Tinggi (m) & Volume (m3) \\
\hline Hopper & 8.93 & 5.58 & 4.58 & 228.21 \\
\hline \multicolumn{5}{|c|}{ Toal Volume (m3) } \\
\hline
\end{tabular}

\section{Volume Surge Bin}

Surge bin pada PT X berfungsi sebagai penampung material dari tahapan secondary crusher sehingga dapat didistribusikan menuju tahap tertiary crusher. Ukuran surge bin pada PT X yaitu, panjang 7,1 m, lebar 5,38 $\mathrm{m}$ dan tinggi 4,87 $\mathrm{m}$. Volume surge bin dapat dilihat pada tabel 2.

Tabel 2. Dimensi Surge Bin

\begin{tabular}{|c|c|c|c|c|}
\hline Alat & Panjang (m) & Lebar (m) & Tinggi (m) & Volume (m3) \\
\hline Surge Bin & 7.1 & 5.38 & 4.87 & 186.02 \\
\hline \multicolumn{5}{|c|}{ Toal Volume (m3) } \\
\hline
\end{tabular}

\section{Belt conveyor}

Belt conveyor digunakan untuk mengangkut dan memindahkan feed serta produkta pada tahapan crushing plant. Terdapat 19 rangkaian belt conveyor di PT X dengan kegunaan yang berbeda. Spesifikasi belt conveyor dapat dilihat pada tabel 3.

Tabel 3. Spesifikasi Belt conveyor

\begin{tabular}{|l|c|c|c|c|c|}
\hline $\begin{array}{c}\text { Belt } \\
\text { conveyor }\end{array}$ & $\begin{array}{c}\text { Panjang } \\
(\mathbf{m})\end{array}$ & $\begin{array}{c}\text { Lebar } \\
(\mathbf{m})\end{array}$ & $\begin{array}{c}\text { Kemiringan } \\
(\mathbf{o})\end{array}$ & Daya HP & $\begin{array}{c}\text { Jumlah } \\
\text { lapisan Belt }\end{array}$ \\
\hline BC 00 & 6 & 0.75 & 10 & 10 & 4 \\
\hline BC 01 & 23 & 0.75 & 10 & 10 & 4 \\
\hline BC 01A & 21 & 0.75 & 10 & 10 & 4 \\
\hline BC 02 & 10 & 1.05 & 5 & 20 & 5 \\
\hline BC 03 & 35 & 1.05 & 17 & 40 & 5 \\
\hline BC 04 & 28 & 1.05 & 3 & 25 & 5 \\
\hline BC 05 & 33 & 1.2 & 10 & 40 & 4 \\
\hline BC 06 & 34 & 0.9 & 10 & 30 & 4 \\
\hline BC 07 & 34 & 0.9 & 10 & 30 & 4 \\
\hline BC 08 & 6 & 0.75 & 10 & 20 & 4 \\
\hline BC 08A & 5 & 0.75 & 14 & 30 & 4 \\
\hline BC 07A & 34 & 0.75 & 10 & 25 & 4 \\
\hline BC 09 & 26 & 0.8 & 10 & 15 & 4 \\
\hline BC 10 & 26 & 0.8 & 10 & 20 & 4 \\
\hline BC 11 & 26 & 0.8 & 10 & 20 & 4 \\
\hline BC 12 & 32 & 0.8 & 10 & 25 & 4 \\
\hline BC 13 & 32 & 0.75 & 10 & 20 & 4 \\
\hline
\end{tabular}




\begin{tabular}{|l|l|l|l|l|l|} 
BC 14 & 23 & 0.6 & 10 & 10 & 4 \\
\hline BC 15 & 23 & 0.6 & 10 & 10 & 4 \\
\hline
\end{tabular}

\section{Waktu Kerja Produktif}

Waktu kerja produktif dilakukan di PT X dilakukanya penelitan selama 30 hari yang dilakukan pada tanggal 08 November 2021 - 04 Desember 2021, waktu produktif kerja yang diperoleh selama 7,8 jam/hari. Jadwal kerja PT X dapat dilihat pada tabel 4.

Tabel 4. Jadwal Kerja PT X

\begin{tabular}{|l|c|c|c|c|}
\hline \multirow{2}{*}{\multicolumn{1}{|c}{ Kegiatan }} & \multicolumn{4}{c|}{ Waktu } \\
\cline { 2 - 5 } & Senin-Kamis dan Sabtu & Menit & Jum'at & Menit \\
\hline Masuk Kerja & 07.00 & 0 & 07.00 & 0 \\
\hline Persiapan Kerja & $06.30-07.00$ & 30 & $06.30-07.00$ & 30 \\
\hline Kerja Produktif 1 & $07.00-12.00$ & 300 & $07.00-11.00$ & 240 \\
\hline Istirahat & $12.00-13.00$ & 60 & $11.00-13.00$ & 60 \\
\hline Kerja Produktif 2 & $13.00-16.00$ & 180 & $13.00-16.00$ & 180 \\
\hline Waktu Kerja Tersedia & & 570 & & 570 \\
\hline Waktu Kerja Produktif & 480 & 420 \\
\hline WP (menit/hari) & \multicolumn{3}{|c|}{770} & \\
\hline WP (jam/hari) & 7.83 \\
\hline
\end{tabular}

\section{Waktu Efektif}

Waktu kerja efektif merupakan waktu yang didapatkan dari waktu produksi dan waktu hambatan yang terjadi selama proses produksi berlangsung. Nilai rata-rata waktu repair sebesar 0,40 jam/hari dan waktu stand by $0.10 \mathrm{jam} /$ hari sehingga total rata-rata waktu efektif sebesar 7.32 jam/hari. Nilai waktu efektif tahapan crushing plant dapat dilihat pada tabel 5.

Tabel 5. Waktu Efektif Crushing plant

\begin{tabular}{|l|r|r|r|r|}
\hline \multicolumn{1}{|c|}{ Tahapan } & $\begin{array}{c}\text { Waktu Produktif } \\
\text { Jam/Hari }\end{array}$ & $\begin{array}{c}\text { Repair } \\
\text { Jam/Hari }\end{array}$ & $\begin{array}{c}\text { Stand By } \\
\text { Jam/Hari }\end{array}$ & $\begin{array}{c}\text { Waktu Efektif } \\
\text { Jam/Hari }\end{array}$ \\
\hline Primary crushing & 7.83 & 0.46 & 0.13 & 7.23 \\
\hline Seccondary Crushing & 7.83 & 0.35 & 0.16 & 7.33 \\
\hline Tertiary crushing & 7.83 & 0.40 & 0.02 & 7.41 \\
\hline Rata-Rata & 7.83 & 0.40 & 0.10 & 7.32 \\
\hline
\end{tabular}

\section{Efisiensi Kerja}

Perhitungan waktu efisiensi kerja crushing plant menggunakan waktu produktif (Senin - Sabtu) mempunyai rata-rata sebesar 439,36 jam/hari dan waktu efektif rata-rata sebesar 470 jam/hari, didapatkan nilai efisiensi kerja rata-rata 93,48\%. Nilai efisiensi kerja crushing plant dilihat pada tabel 6.

Tabel 6. Efisiensi Kerja Crushing plant

\begin{tabular}{|l|r|r|r|r|}
\hline \multicolumn{1}{|c|}{ Hasil } & $\begin{array}{l}\text { Rata-Rata } \\
\text { Tahapan }\end{array}$ & $\begin{array}{l}\text { Primary } \\
\text { crushing }\end{array}$ & $\begin{array}{l}\text { Seccondary } \\
\text { Crushing }\end{array}$ & $\begin{array}{l}\text { Tertiary } \\
\text { crushing }\end{array}$ \\
\hline waktu efektif (we) menit/hari & 439.36 & 433.89 & 439.57 & 444.61 \\
\hline waktu profuktif (wp) menit/hari & 470 & 470 & 470 & 470 \\
\hline efesiensi kerja (E) \% & 93.48 & 92.32 & 93.53 & 94.60 \\
\hline
\end{tabular}




\section{Avaibility Crushing Plant}

Berdasarkan data waktu efektif, waktu repair dan waktu stand by masing- masing alat primary crusher, secondary crusher, dan tertiary crushing didapatkan rata-rata nilai mechanical availability $94,77 \%$, physical avaibility $94.83 \%$, use of availibility 98,62\% dan efective of utilization 93,52\%. Nilai avaibility crushing plant dilihat pada tabel 7.

Tabel 7. Avaibilitity Crushing Plant

\begin{tabular}{|l|r|r|r|r|}
\hline \multicolumn{1}{|c|}{ Tahapan Pengolahan } & $\begin{array}{c}\text { Machanical } \\
\text { Avaibility } \\
(\%)\end{array}$ & $\begin{array}{c}\text { Physical } \\
\text { Avaibility } \\
(\%)\end{array}$ & $\begin{array}{c}\text { Use of } \\
\text { Availibility } \\
(\%)\end{array}$ & $\begin{array}{c}\text { Efeective of } \\
\text { Utilization } \\
(\%)\end{array}$ \\
\hline Jaw crusher & 93.96 & 94.06 & 98.19 & 92.36 \\
\hline Cone crusher I & 95.47 & 95.56 & 97.92 & 93.57 \\
\hline Cone crusher II dan III & 94.87 & 94.88 & 99.75 & 94.64 \\
\hline Rata-Rata & 94.77 & 94.83 & 98.62 & 93.52 \\
\hline
\end{tabular}

\section{Produksi Alat Angkut}

Produksi alat angkut diperoleh dari hasil perhitungan, ritase alat angkut (Hino dan Tonly), ratarata pemuatan (Excavator Kobelco SK-330), fill factor, density loose, dan kapasitas bucket (Excavator Kobelco SK-330) diperoleh produksi 400.77 ton/jam, Nilai produksi alat angkut dapat dilihat pada tabel 8.

Tabel 8. Produksi Alat Angkut

\begin{tabular}{|l|c|c|}
\hline Parameter & Nilai & Satuan \\
\hline Rata-Rata Ritase & 167.59 & rit \\
\hline Rata-Rata Pemuatan & 10 & kali \\
\hline Fill Factor & 0.71 & $\%$ \\
\hline Density Loose & 1.65 & ton/LCM \\
\hline Kapasitas Bucket (Kobelco SK-330) & 1.6 & LCM \\
\hline Produksi & 400.77 & ton/jam \\
\hline
\end{tabular}

\section{Produksi Belt Cut}

Perhitungan produksi menggunakan metode belt cut dari data perkalian antara berat sampel dalam 1 meter dan kecepatan belt conveyor yang dilakukan sebanyak 19 kali. Perhitungan belt conveyor secara aktual dilihat pada tabel 9.

Tabel 9. Produksi Belt Cut

\begin{tabular}{|l|c|c|c|c|c|}
\hline \multirow{2}{*}{ Belt Cut } & \multicolumn{2}{|c|}{ SPEED } & BERAT & \multicolumn{2}{c|}{ KAPASITAS } \\
\cline { 2 - 6 } & $\mathbf{m} / \mathbf{m e n i t}$ & $\mathbf{m} / \mathbf{j a m}$ & $\mathbf{k g}$ & $\mathbf{k g / j a m}$ & $\mathbf{t} / \mathbf{j a m}$ \\
\hline BC 00 & 120.2 & 7212 & 2.43 & 17525 & 17.53 \\
\hline BC 01 & 118.01 & 7080.6 & 2.4 & 15152 & 16.99 \\
\hline BC 01A (Sirdam) & 118.04 & 7082.4 & 2.21 & 15652 & 15.65 \\
\hline BC 02 & 117.5 & 7050 & 54.59 & 384860 & 384.86 \\
\hline BC 03 & 117.8 & 7068 & 54.4 & 384711 & 384.71 \\
\hline BC 04 & 118.1 & 7086 & 54.31 & 384841 & 384.84 \\
\hline BC 05 & 118.23 & 7093.8 & 54.23 & 384697 & 384.70 \\
\hline BC 06 & 120 & 7200 & 22.69 & 163368 & 163.37 \\
\hline BC 07 & 119.95 & 7197 & 22.6 & 162652 & 162.65 \\
\hline BC 8 (Return) & 118.59 & 7115.4 & 3.2 & 22769 & 22.77 \\
\hline BC 08A (bypass 1) & 119.5 & 7170 & 8.2 & 65964 & 58.78 \\
\hline
\end{tabular}




\begin{tabular}{|l|c|c|c|c|c|} 
BC 07A (bypass 2) & 122 & 7320 & 8 & 58560 & 58.56 \\
\hline BC 9 (Split 23) & 120.5 & 7200 & 10.7 & 77040 & 77.04 \\
\hline BC 10 & 117 & 7020 & 19.99 & 140330 & 140.33 \\
\hline BC 11 & 119 & 7140 & 20.22 & 144371 & 144.37 \\
\hline BC 12 (Split 12) & 119.5 & 7185 & 23.2 & 166692 & 166.69 \\
\hline BC 13 (screening) & 121.4 & 7284 & 6.26 & 45598 & 45.60 \\
\hline BC 14 (Abu batu) & 125 & 7500 & 4.75 & 35625 & 35.63 \\
\hline BC 15 (Abu batu) & 125.29 & 7517.4 & 4.89 & 36760 & 36.76 \\
\hline
\end{tabular}

\section{Material Balance}

Lossing materials dihitung berdasarkan jumlah feed masuk dan produkta hasil pengolahan, perhitungan loose dibagi berdasarkan dari tahapan crushing plant. Lossing materials primary crushing sebesar 0,25, secondary crushing 0,16, tertiary crushing 0,14, sizing 1 sebesar 0,07 dan sizing 2 sebesar 0,03. Perhitungan losing materials dilihat pada tabel 10.

Tabel 10. Material Balance

\begin{tabular}{|c|c|c|c|c|}
\hline Tahapan Pengolahan & $\begin{array}{c}\text { Umpan } \\
\text { Masuk } \\
\text { (Ton/Jam) } \\
\end{array}$ & $\begin{array}{c}\text { Umpan } \\
\text { Keluar } \\
\text { (Ton/Jam) } \\
\end{array}$ & $\begin{array}{c}\text { Jumlah loosses } \\
\text { Material } \\
\text { (Ton/Jam) }\end{array}$ & $\begin{array}{c}\% \text { Loose } \\
\text { Terhadap Feed }\end{array}$ \\
\hline Primary crushing & 385.11 & 384.86 & 0.25 & 0.065 \\
\hline Seccondary & 384.84 & 384.70 & 0.14 & 0.037 \\
\hline Tertiary & 384.70 & 384.58 & 0.12 & 0.030 \\
\hline Return & & 22,77 & & \\
\hline \multirow{2}{*}{ Sizing 1} & \multirow{2}{*}{384.58} & 22.77 & \multirow{2}{*}{0.07} & \multirow{2}{*}{0.018} \\
\hline & & 361.74 & & \\
\hline Split 2-3 & & 77.04 & & \\
\hline \multirow{2}{*}{ Sizing 2} & \multirow{2}{*}{361.74} & 77.04 & \multirow{2}{*}{0.03} & \multirow{2}{*}{0.008} \\
\hline & & 284.67 & & \\
\hline
\end{tabular}

\section{Production Rate Index}

Production rate index (PRI) diperoleh dari produksi aktual (tph) dan nilai kapasitas produksi (tph). Berdasarkan tahapan pengolahan mesin primary crusher (jaw crusher) mempunyai nilai PRI sebesar $90 \%$, secondary crusher (cone crusher 01) 85\%, tertiary crusher (cone crusher 01 dan cone crusher 02) 74\%. Nilai production rate index dapat dilihat pada tabel 11.

Tabel 11. Production Rate Index

\begin{tabular}{|l|c|c|c|c|}
\hline \multicolumn{5}{|c|}{ PRODUCTION RATE INDEX } \\
\hline $\begin{array}{l}\text { Tahapan } \\
\text { Pengolahan }\end{array}$ & Mesin Crusher & $\begin{array}{c}\text { Produksi Asumsi } \\
\text { (tph) }\end{array}$ & $\begin{array}{c}\text { Kapasitas Produksi } \\
\text { (tph) }\end{array}$ & PRI \\
\hline Primary crushing & Jaw crusher & 384.86 & 430 & $90 \%$ \\
\hline Secondary Crusher & Cone crusher 1 & 384.70 & 450 & $85 \%$ \\
\hline \multirow{2}{*}{ Tertiary Crusher } & Cone crusher 2 & 163.37 & 220 & $74 \%$ \\
\cline { 2 - 5 } & Cone crusher 3 & 162.65 & 220 & $74 \%$ \\
\hline
\end{tabular}

\section{Reduction Ratio}

Reduction ratio merupakan rasio perbandingan antara ukuran feed dan ukuran produkta pada JRTP is licensed under Creative Commons Attribution- 
mesin crusher berdasarkan data spesifikasi open side setting dan close side setting pada alat crusher. Berdasarkan tahapan pengolahan primary crusher mempunyai nilai reduction ratio sebesar $8,2 \%$, secondary crusher 3,1, tertiary crusher 2.0. Nilai reduction ratio dapat dilihat pada tabel 12 .

Tabel 12. Reduction Ratio

\begin{tabular}{|l|c|c|c|c|}
\hline \multicolumn{5}{|c|}{ Reduction Ratio } \\
\hline Tahapan Pengolahan & $\begin{array}{c}\text { Open Side } \\
\text { Setting }(\mathrm{cm})\end{array}$ & $\begin{array}{c}\text { Close Side } \\
\text { Setting }(\mathrm{cm})\end{array}$ & $\begin{array}{c}\text { Reduction } \\
\text { Ratio }\end{array}$ & Kategori \\
\hline Primary Cruhsing & 140 & 17 & 8,2 & Sangat Baik \\
\hline Secondary crushing & 17 & 5,5 & 3,1 & Baik \\
\hline Tertiary crushing & 5,5 & 2,8 & 2,0 & Baik \\
\hline
\end{tabular}

\section{Kesimpulan}

Berdasarkan hasil penelitian, dapat ditarik kesimpulan, yaitu :

1. Hambatan terbagi menjadi repair dan stand by, rata-rata waktu stand by pada tahapan primary crushing sebesar $0,13 \mathrm{jam} / \mathrm{hari}$, secondary crushing $0,16 \mathrm{jam} / \mathrm{hari}$ dan tertiary crushing $0,019 \mathrm{jam} / \mathrm{hari}$. Waktu rata-rata waktu repair pada tahapan primary crushing sebesar 0,46 jam/hari, secondary crushing $0,35 \mathrm{jam} / \mathrm{hari}$ dan tertiary crushing 0,40 jam/hari.

2. Mechanical availabillity didapatkan nilai kondisi alat mekanis sebesar $94,77 \%$, keadaan fisik dari alat (physichal availability) sebesar 94,83\%, dan nilai efisiensi kerja (efective of utilization) sebesar 93,52\%.

3. Primary crushing losses materials sebesar 0,25 dengan persentase $0,066 \%$, secondary crushing sebesar 0,16 persentase $0,042 \%$, tertiary crushing sebesar 0,14 dengan persentase $0,038 \%$, sizing 1 sebesar 0,07 dengan persentase $0,019 \%$, dan sizing 2 sebesar 0,03 dengan persentase $0,009 \%$

4. Produksi produk yang dihasilkan dari unit crushing plant yaitu 77,04 ton/jam split 2-3, 166,69 ton/jam split 1-2, 45,60 ton/jam screening, 35,63 ton/jam abu batu 1, 36,79 ton/jam abu batu 2 dan 15,65 ton/jam base course, total keseluruhan produk sebesar 377,37 ton/jam.

\section{Acknowledge}

Terima kasih kepada Bapak Dr. Ir. Yunus Ashari, M.T. selaku Ketua Prodi, Bapak Noor Fauzi Isniarno, S.Si.,S.Pd., M.T. selaku Sekretaris Prodi, Ibu Sriyanti, S.T., M.T. selaku Pembimbing, Ibu Elfida Moralista, S.SI., M.T. selaku Co-Pembimbing sekaligus wali dosen serta semua Dosen dan Staff yang senantisa memberikan doa, dukungan, motivasi kepada penyusun. Terima kasih kepada kedua orang tua, Ir. Elyadi dan Endang Juwita, terimakasih selalu memberikan doa maupun dukungan terbaik. Adik tercinta, M. Rezaldy Eliansyah, Farah Fatarissa Eliansyah, M. Ikshan Eliansyah, M. Iqbal Eliansyah dan M. Nazriel Eliansyah yang telah memberikan dukungan dan motivasi kepada penyusun. Terima kasih kepada PT X yang sudah memberikan kesempatan penulis untuk melaksanakan penelitian. Terima kasih karena tidak pernah lelah menjadi dukungan terbaik, semangat tertinggi dalam menjalani kuliah selama ini. Hidup Tambang, Kuat Tambang, Jaya Tambang.

\section{Daftar Pustaka}

[1] Anonim, 2003, "Conveyor Belt Design Manual, Bridgestone Corporation” Tokyo, Japan.

[2] Anonim, 2018, "Basic in Mineral Processing" Metso, Corporation.

[3] A R.L. 1960, "Geology Of The Industrial Rocks And Minerals" Harper and Raw Publisher, New York

[4] Anonim, 2021, "Kecamatan Rumpin Dalam Angka" Badan Pusat Statistik (BPS), Kecamatan Rumpin. 
[5] Bates, R.L. 1960, "Geology Of The Industrial Rocks And Minerals" Harper and Raw Publisher, New York

[6] Blatt, H. and Tracy, R.J., 1996, "Petrology" Freeman.

[7] Gaudin. 1939, "Crushing and Grinding, Butterworth's", London, England.

[8] Gustav, Tarjan, 1981, "Mineral Processing Technology", Akademia Kiado, Budapest.

[9] Harris, J.W., Stockker, 1988, "Handbook of Mathematics and Compulational Science", Springer, New York.

[10] Keputusan Menteri Energi dan Sumberdaya Mineral Nomor 1827 K/30/MEM/2018 tentang Pedoman Pelaksanaan Kaidah Teknik Pertambangan Yang Baik, Kementerian Energi dan Sumberdaya Mineral, Jakarta, Indonesia.

[11] Peraturan Daerah Kabupaten Bogor Nomor 19 Tahun 2008 Tentang Rencana Tata Ruang Wilayah (RTRW) Kabupaten Bgor Tahun 2005-2025, Pemerintah Daerah Kabupaten Bogor, Indonesia.

[12] Prodjosumarto, Partanto, 1993, "Pemindahan Tanah Mekanis", Jurusan Teknik Pertambangan, Institut Teknologi Bandung.

[13] Soewarno, 2015, "Seri Hidrologi Klimatologi”, Graha Ilmu, Yogyakarta, Indonesia

[14] Taggart, Arthur F, 1944, "Handbook of Mineral Dressing", Wiley-Interscience Publication, New York. 